\title{
La diacronía como análisis semiótico de la identidad gráfica de HMV
}

Por: Leidy Milena Ramírez Ibáñez 
A causa de la problemática de estudio, enfocada a la identidad corporativa y la creación de símbolos en la publicidad para producir mayor recordación en la cultura, y como argumento a esta enunciación, se establece que la iconicidad del perro y el gramófono se volvió símbolo de las marcas durante 116 años, así este objeto ya no se utilice y el perro haya muerto, se conservan valores simbólicos que permiten persuadir e identificar a los receptores, donde, así cambie de nombre la compañía, la imagen guardará un mensaje connotado de lealtad.

\section{Inicios de la identidad gráfica}

Para iniciar el análisis lo asociaremos, primeramente, con el Triángulo Semiótico de Peirce (1974), estudiando el proceso que tiene el objeto para convertirse en un signo desde la semiótica, relacionando la identidad de Nipper y el gramófono como 'ícono', puesto que se hace una representación por semejanza. Esta la hace Francis a través de la pintura, posteriormente pasa a ser un 'símbolo' porque a través del tiempo fue instalandose y apropiándose en la sociedad, es por eso que se da como una representación ideológica porque es la cultura y no la marca la que hace que los íconos tomen un valor simbólico y se instauren en ella; en otras palabras, va más allá de ser un perro que oye un gramófono, por lo que comunica con una intensión persuasiva que busca convencer y generar pregnancia es decir, recordación en la cultura. Por último, se vue ve un 'índice', porque es el efecto que se genera a partir del símbolo, de una representación por causalidad que en este caso sería la lealtad, la fidelidad, la sencillez, el no esperar nada a cambio, etc... En el análisis del triángulo semiótico de Pierce, se establecen dos variaciones en los significados, la denotación y la connotación. Los signos denotativos' remiten al significado siguiendo las reglas de un código. Por ejemplo, es objetivo decir que Nipper es un perro, que es un animal y a la vez un ser vivo, mientras que el gramófono es un objeto para la reproducción musical, en otras palabras, una cosa. 
Primero, el mensaje lingüístico se : refiere al lenguaje articulado (escrito) que: forma parte de la misma imagen, en este : caso ese mensaje seria el slogan "His Master's Voice". El mensaje lingüístico tiene diferentes funciones: que son: 'Función de anclaje', “His Master's Voice”, es el soporte o apoyo de la imagen que se convierte en leyenda, que ancla todos sentidos denotados, es : decir, que identifica a los objetos como el gramófono : y a Nipper. A nivel de mensaje simbólico, el lingüístico : guía, ya no el reconocimiento, sino la interpretación : y constituye una tenaza que impide que los sentidos: connotados se desorientan. En otras palabras, se limita el poder proyectivo de la imagen.

Luego, la 'función de relevo', esta es menos frecuente que la anterior, y se encuentra usualmente en comics porque la mezcla del texto y la imagen es inseparable, en tanto posee una carga informática connotada en la : que el significado está en las palabras y la imagen es el acompañamiento. Se da en las múltiples representaciones que han surgido a través del tiempo, a partir de la imagen original se han creado nuevos significados, como los que ha hecho el artista Royston Robertson, quien se dedica a dibujar tiras cómicas, caricaturas e : ilustraciones de humor. Robertson ha realizado una serie de dibujos cómicos y su tema principal es Nipper y el gramófono, en donde le da vida a Nipper y lo personifica a través de diferentes actitudes o situaciones en las que se ve implicado con el gramófono, en relación : con el pasado y la evolución del pensamiento y de la tecnología.

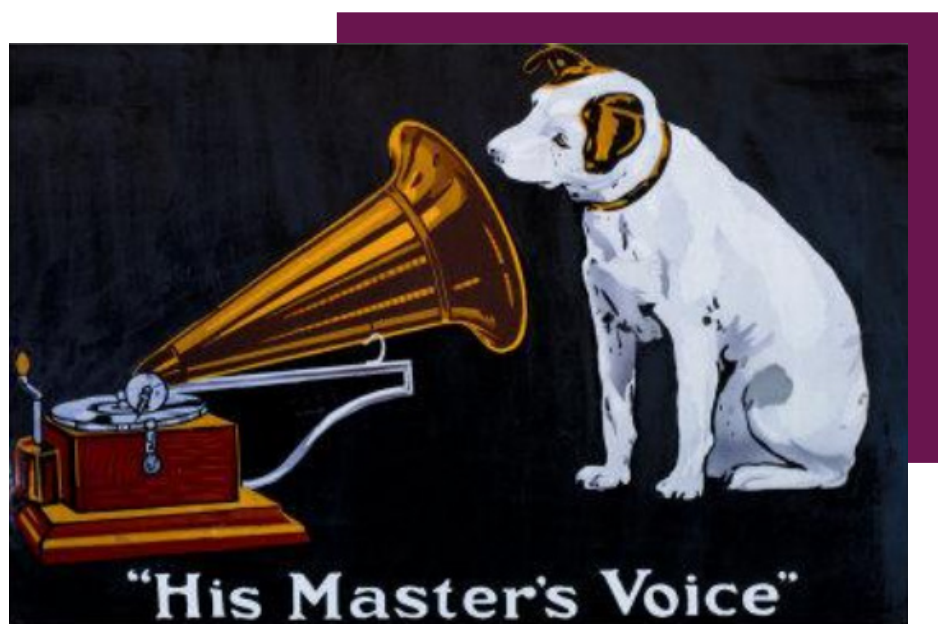

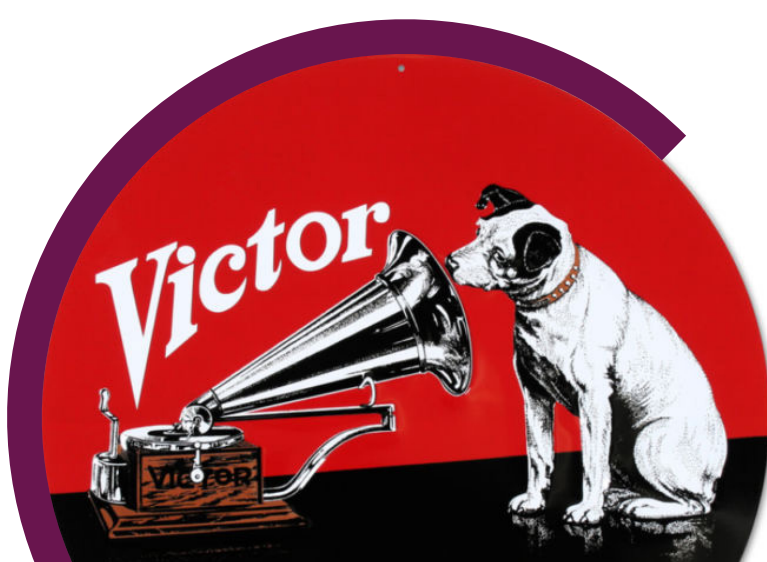

\section{“HIS MASTER'S VOICE"}

REG. U.S. PAT. OFF

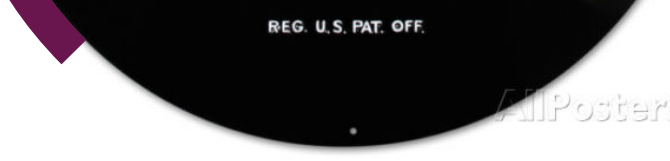

Logo VTM

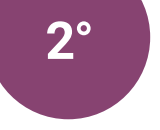

Segundo, el 'mensaje icónico literal', acotado por la denotación, que requiere solamente la percepción en la que se enumeran los elementos, se explica y se describe la relación de los mismos de manera formal, haciendo una lectura en primer nivel. La imagen literal es la imagen denotada, a la que le pertenece una identificación natural entre el significante y el significado. En este caso el logo de VTM, muestra a un gramófono y al frente, un perro que está sentado con su cabeza inclinada lateralmente observando el gramófono. En la parte posterior un slogan en mayúsculas titulado "His Master's Voice"; todos los elementos están encerrados en una forma circular con un fondo rojo con negro.
Imagen HMV

"His Master^s Voice" 
lico', atiende al concepto de connotación, es decir, a la capacidad interpretativa de los receptores a los mensajes no explícitos que se generan a partir de la imagen, haciendo una lectura asociada a diferentes saberes; en una de las piezas gráficas de la publicidad VTM: Victor Talking Machine, hecha en litografía, el mensaje que se quiere transmitir es una analogía a través de la imagen de cómo Nipper comparte un sentimiento tan profundo con el gramófono, que trasciende de ser el objeto en el que él oye la voz de su amo, para convertirse en un vehículo llamado "Gramomobil", al que no dejará así tenga la necesidad de ir a otras partes puesto que trasmite la capacidad del gramófono de ser un objeto que puede ser llevado con facilidad a todas partes para la comodidad de los usuarios que lo han adquirido a través de

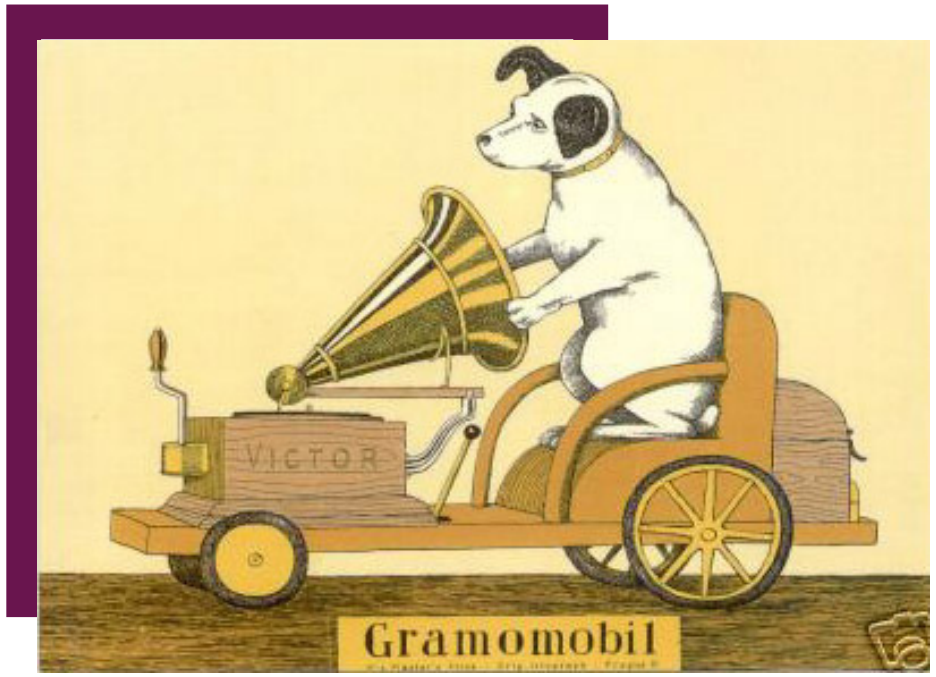

Pieza gráfica publicidad Victor Talking Machine la compañía. De ahí que, 'la imagen denotada', sea la distinción entre el mensaje literal y el mensaje simbólico. Las características del mensaje literal no pueden ser entonces sustanciales, sino tan sólo relacionales.

Continuando con 'la retórica de la imagen', como valor simbólico que se genera en el espectador a partir de una ideología, es un proceso ideológico-cultural. Se refiere a lo que connota una imagen, esto está relacionado con factores históricos (porque cambia con el tiempo), sociales (no es individual, es social, tiene que ver con el sentido común), y culturales (porque no es natural, si no que se origina en la cultura). Por ejemplo, la fidelidad y el amor de Nipper hacia su amo se expresa en la imagen a través de la figura retórica de la personificación, que consiste en atribuir una cualidad humana a un objeto inanimado (gramófono).

También se utiliza esta figura retórica en una pieza publicitaria alusiva a la muerte del legendario músico inglés David Bowie, el 10 de enero de 2016, por ser un ícono musical, que se relaciona con la marca que es dedicada a la comercialización musical.

Otro ejemplo clave sería la imagen publicitaria de HMV, compañía actual que utiliza la imagen de Nipper como logo, que utiliza el recurso de retórica en la imagen a través de la onomatopeya, para publicar la pérdida anual como caída de las ventas.

\section{"HIS MASTER'S VOICE"}

("LA VOZ DE SU AMO")
"MASTER'S HIS VOICE"

("SU VOZ DEL AMO")

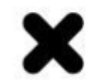


Por añadidura a esta teoría, es importante traer a colación a Charles William Morris, alumno de Pierce. Como punto de partida, la 'sintaxis' es la relación lógica que existe entre las lenguas articuladas y los acuerdos sociales en el sistema de los signos como los idiomas, las señales de tránsito, o cualquier sistema que se halla conformado y establecido estrechamente en la sociedad; es decir la relación formal de los signos entre sí, que permiten la formación y transformación de: signos, palabras, oraciones y textos como un universo infinito. Por ejemplo \#1, ‘His Master's Voice' (la voz de su amo) = Slogan de las marcas de reproducción musical. Ejemplo 2: si alguien dice 'Master's His Voice' (su voz del amo) para informar “La voz de su amo", apenas se entendería, puesto que su locución está llena de incorreciones sintácticas esto se debe a la intercalación de las palabras que alteran su orden lógico. Como resultado, el signo pierde su legibilidad y lecturabilidad.

Seguido de la 'semántica', como la relación entre los signos y su significado a partir del orden y las palabras adecuadas para la comprensión del mensaje.Por ejemplo, si se quiere decir que Nipper y el gramófono guardan una relación significativa, se deben usar las palabras adecuadas para comprender lo que quiere transmitir el mensaje; por ello, no sería correcto decir Nipper y el gramófono están comprometidos, si bien tiene razón y sintácticamente es correcto, no transmite el mensaje de manera adecuada. Una de las formas correctas sería "Nipper escucha la voz de su amo a través del gramófono"; en esta oración el mensaje resulta más claro y preciso.
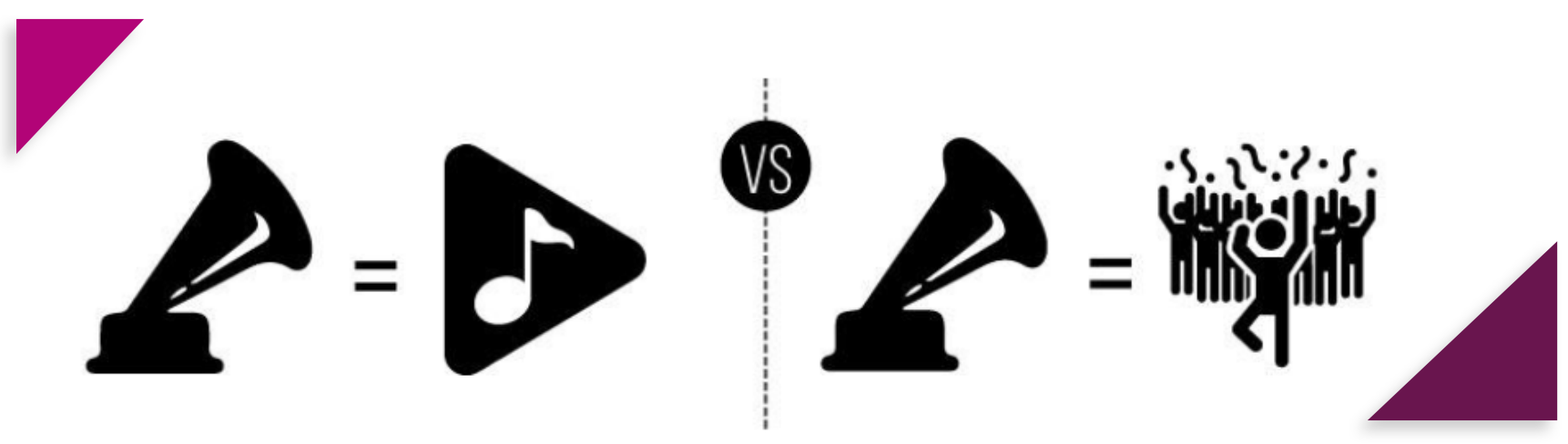

\footnotetext{
: Y por último la 'pragmática', como la relación a partir de los signos lingüísticos y los contextos o realidades en las que son utilizadas, y que se relacionan con el sujeto a partir de experiencias, sentimientos y sentidos. Se aborda así al signo a través de la interpretación circunstancial subjetiva. Ejemplo 1, (Gramófono = Reproducción); en la experiencia del objeto 'gramófono' se percibe como el instrumento electromecánico mediante el cual se logra la grabación y reproducción del sonido a partir de un disco plano. Ejemplo 2, (Gramófono = : Entretenimiento); el mismo objeto "gramófono" se ha cambiado de contexto y ahora cumple una función de esparcimiento a través de sus resonancias.
} 

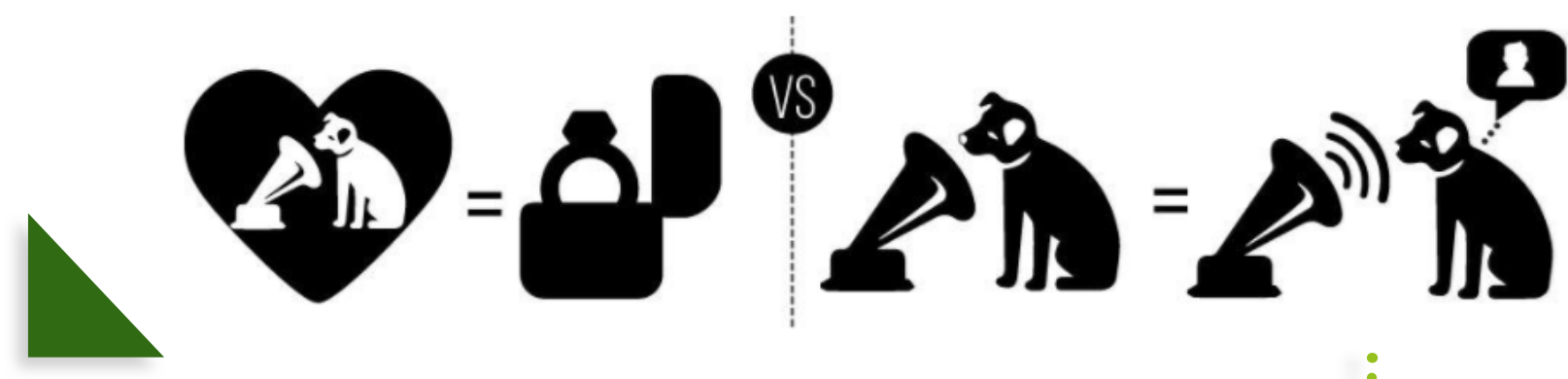

Según Peirce "Todo símbolo es un ícono, pero no todo ícono es un símbolo.", en otras palabras, se puede decir que toda representación ideológica cultural, pasa primero a ser por semejanza y la cultura es la encargada de establecerla; pero toda representación por semejanza no puede ser aceptada con exactitud o de la misma forma por la cultura, si por el contrario no la representa e identifica en ningún contexto. Lo que ha establecido el valor simbólico de Nipper y el gramófono para HMV a través del tiempo, quien se ha encargado de posicionar la marca que resulta ser familiar y confiable para los usuarios por su trayectoria en más de 100 años, es la pregnancia en una identidad gráfica que se debe forjar con elementos conexos, que a su vez guarden una relación de dependencia.

\section{Lista de Referencias}

Peirce, C. S. (1974). La ciencia de la semiótica (p. 29). Buenos Aires: Nueva Visión.

Barthes, R. (1986). Retórica de la imagen. Lo obvio y lo obtuso, 29-47.

Morris, C. W., \& Comunicación; 14. (1994). Fundamentos de la teoría de los signos. Paidós. 


\section{LA IDENTIDAD GRÁFICA DE HMV}

La investigación se da a partir del análisis semiótico de la identidad de marca, en relación pregnante con el usuario a través del tiempo.

Índice: se concibe a partir del símbolo, y se manifiesta como una representación por la causalidad del gramófono y Nipper
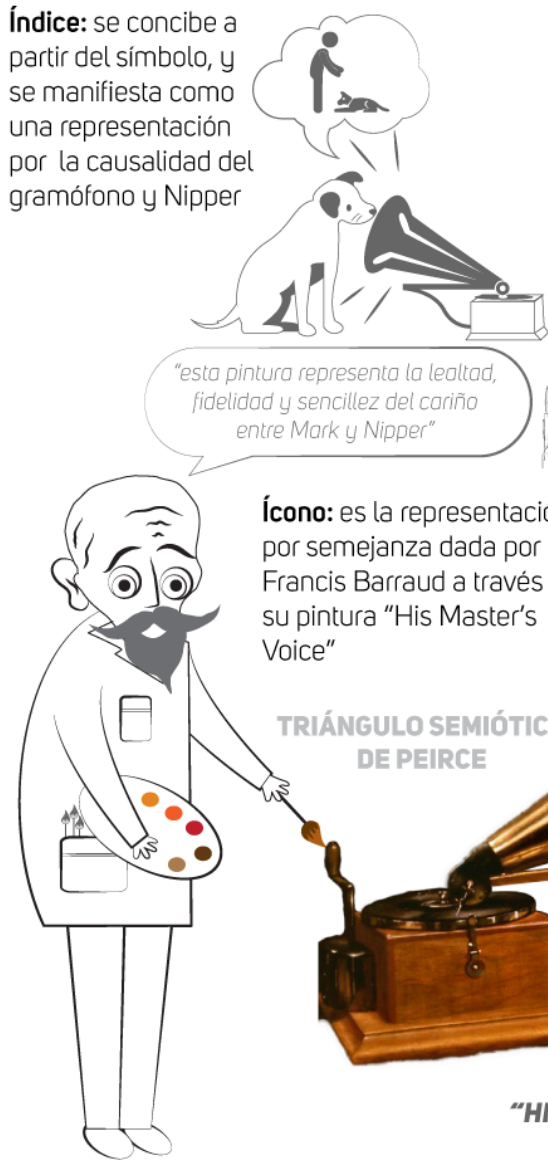

Ícono: es la representación

por semejanza dada por

Francis Barraud a través de

su pintura "His Master's

Voice"

TRIÁNGULO SEMIÓTICO DE PEIRCE

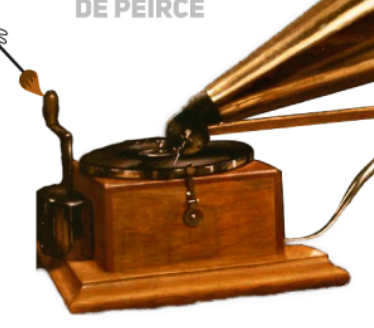

"HIS MASTER'S VOICE" $\checkmark$
Símbolo: es la representación ideológica porque es la cultura y no la marca, quién hace que los íconos tomen un valor símbolico pregnante y se instaure en ella
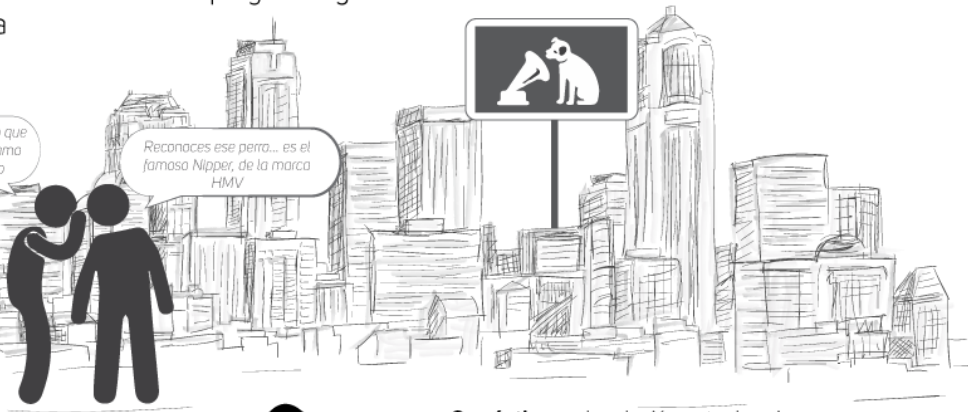

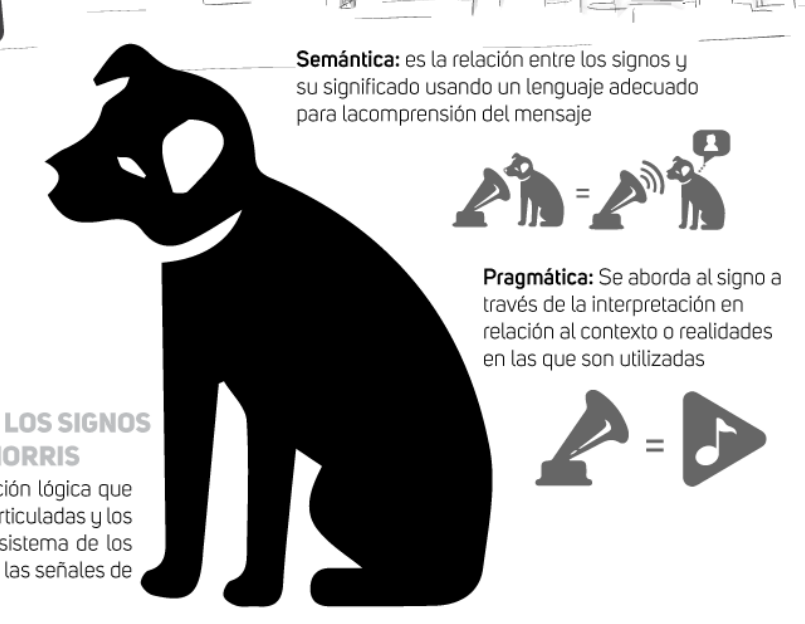

Sintaxis: es la es la relación lógica que existe entre las lenguas articuladas y lo acuerdos sociales en el sistema de los signos como los idiomas, las señales de "MASTER'S HIS VOICE"

$\mathbf{x}$

IIS MASTER'ㅁOICE 
Obra de arte (1889)

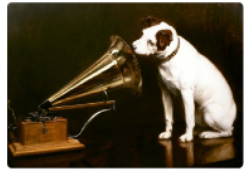

Francis Barraud, hermano de Mark, quién era el dueño de Nipper, y tras fallecer su hermano, heredo a su perro y otras pertenencias, entre ellas un fonógrafo. Una noche, a Francis, se le ocurrió escucha las grabaciones de su difunto hermano, en su viejo fonógrafo, y al hacerlo, Nipper se acerco con gran interes en la bocina atentamente.

Decidio tomarle una fotografia, y un día, mientras Francis organizaba sus cosas, encontró fotografia de Nipper. Como era un gran pintor, tuvo la idea de plasmar esa fotografía, en una tela al óleo.
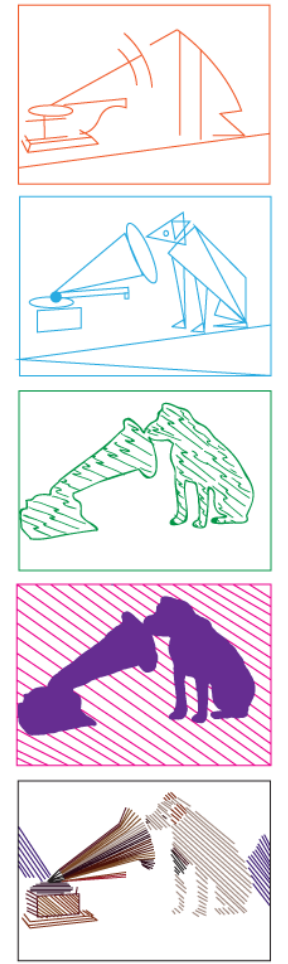

Logo inicial (1900)

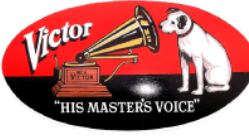

El mensaje icónico literal acotado por la denotación es la percepción formal de los elemenoos como el logo de VTM, muestra a un gramófono y al frente, un perro que está sentado con su cabeza inclinada lateralmente observando el gramófono en la parte posterior un slogan en mayúsculas; todos los elementos están encerrados en una forma circular con un fondo rojo con negro.
Publicidad (1905)

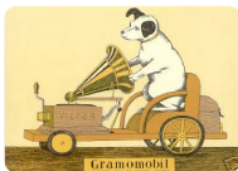

El mensaje icónico símboli$\mathrm{co}$, en una de las piezas gráficas de la publicidad VTM, el mensaje que se quiere transmitir es una analogía a través de la imagen es como Nippe comparte un sentimiento tan profundo con el gramó fono, que trasciende de ser el objeto en el que el oye la voz de su amo, para convertirse un vehículo llamado "Gramomobil".
Representaciones (2012) Publicidad (2014)

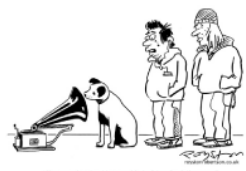

La función de relevo, se da en las múltiples representaciones que han surgido a través del tiempo, a partir de la imagen original sean creado nuevos significados como los que ha hecho el artista Royston Robertson quien se dedica a dibujar tiras cómicas

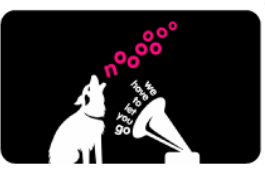

la imagen publicitaria de HMV, compañia actual que utiliza la imagen de Nipper como logo, utiliza el recurso de retórica en la imagen a través de la onomatopeya, para publicar la pérdida anual como caída de las ventas.
Publicidad (2016)

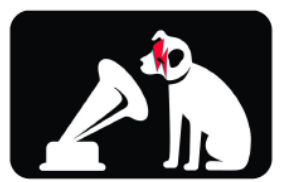

La figura retorica de la personificación, se utiliza en una pieza publicitaria alusiva a la muerte del legendario músico inglés David Bowie, el 10 de enero de 2016; por ser un icono musical, que se relaciona con la marca que es dedicada a la comercialización musical.

\section{ANÁLISIS ICONOGRÁFICO DE PANOFSKY}
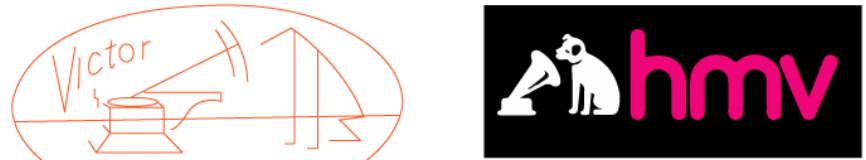

La iconografía es la rama que estudia el contenido temático o significado de las obras de arte; este análisis lo divide en tres niveles: contenido temático natural o primario, contenido secundario o convencional y significado intrínseco o contenido.

Pintura realizada por Francis Barraud (1889). A través del 'contenido temático natural o primario' se puede observar e identificar la etapa descriptiva y formal de la obra. Se enfatiza en elementos formales como: un perro y un gramófono encima de una mesa; se observa un espacio tridimensional en una habitación; en un plano general que cuenta con un acho, largo y profundidad. A partir de las 'capas se puede caracterizar los principales elementos formales.
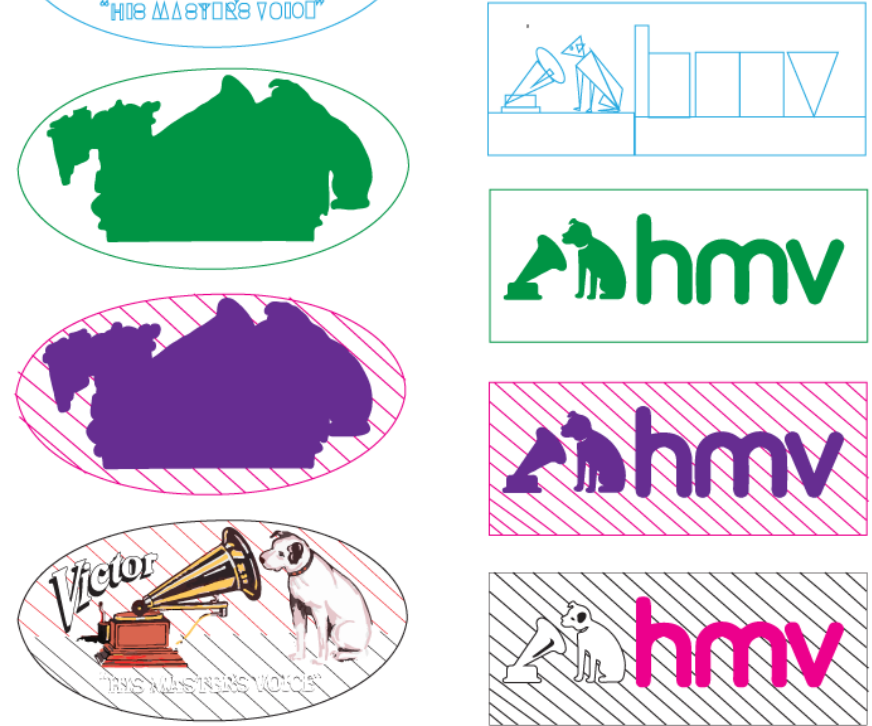

Logo figurativo de la compañía de gramófonos Victor RCA (1929). Esta representación se concibe a partir de la obra original de 'His Master's Voice'.

Logo abstracto de la compañía HMV (2016). Surge a partir de las anteriores compañías que utilizaban una identidad más realista o figurativa.

En conclusión la idea central de este análisis es reconocer como la iconicidad de HMV infiere en la diacronia, posicionándose asi como una de las marcas más reconocidas mundialmente, ha logrado destacarse junto con otras marcas que han acertado en su trabajo de identidad corporativa en la que existen signos que a su vez están establecidos por infrasignos, que a su vez permiten identificar la marca como pregnante, siempre y cuando se respeten los elementos principales, es decir que si los infrasignos de Nipper y el gramófono se altera por ejemplo a Nipper y una grabadora su contenido intrínseco cambiaria totalmente, y como consecuencia la pregnancia desaparecerá porque se cambia el significado y por ende el contexto de la imagen, y por ende se referencia en otra cosa. 